\title{
Associations between maternal employment and time spent in nutrition-related behaviours among German children and mothers
}

\author{
Anke Möser ${ }^{1, *}$, Susan E Chen ${ }^{2}$, Stephanie B Jilcott ${ }^{3}$ and Rodolfo M Nayga Jr ${ }^{4}$ \\ ${ }^{1}$ Center for International Development and Environmental Research, Justus-Liebig University Giessen, \\ Senckenbergstr. 3, D-35390 Gießen, Germany: ${ }^{2}$ Department of Economics, Finance and Legal Studies, \\ University of Alabama, Tuscaloosa, AL, USA: ${ }^{3}$ Department of Public Health, Brody School of Medicine, \\ East Carolina University, Greenville, NC, USA: ${ }^{4}$ Department of Agricultural Economics and Agribusiness, \\ Division of Agriculture, University of Arkansas, Fayetteville, AR, USA and Adjunct Researcher, Norwegian \\ Agricultural Economics Research Institute, Oslo, Norway
}

Submitted 25 February 2011: Accepted 17 November 2011: First published online 21 December 2011

\begin{abstract}
Objective: To examine associations between maternal employment and time spent engaging in nutrition-related behaviours among mothers and children using a nationally representative sample of households in West and East Germany.

Design: A cross-sectional analysis was performed using time-use data for a sample of mother-child dyads. Associations between maternal employment and time spent in nutrition-related activities such as eating at home, eating away from home and food preparation were estimated using a double-hurdle model.

Setting: German Time Budget Survey 2001/02.

Subjects: The overall sample included 1071 households with a child between 10 and 17 years of age. The time-use data were collected for a $3 \mathrm{~d}$ period of observation (two weekdays and one weekend day).

Results: Maternal employment was associated with the time children spent on nutrition-related behaviours. In households with employed mothers, children spent more time eating alone at home and less time eating meals with their mothers. Moreover, employed mothers spent less time on meal preparation compared with non-employed mothers. There were regional differences in time spent on nutrition-related behaviours, such that East German children were more likely to eat at home alone than West German children.

Conclusions: Maternal employment was associated with less time spent eating with children and preparing food, which may be related to the increasing childhood obesity rates in Germany. Future national surveys that collect both time-use data and health outcomes could yield further insight into mechanisms by which maternal time use might be associated with health outcomes among children.
\end{abstract}

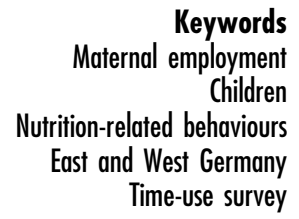

Parents are crucial in helping children to establish healthy eating patterns ${ }^{(1-3)}$. There is increasing evidence that environmental factors within the home, including parental food provisioning and role modelling, can affect the dietary patterns of youngsters ${ }^{(4-6)}$. For example, previously family meals were associated with improved nutritional intake of children and adolescents ${ }^{(7-9)}$. However, these studies have been conducted in the USA, and more work is needed in other contexts, as such associations may be context dependent. Ultimately, it is important for parents to encourage their children to establish healthy behaviours early in life, since dietary behaviours, as well as obesity, often persist into adulthood ${ }^{(10,11)}$.

Research on time spent in household production activities, such as eating at home and food preparation, indicates that adults, and women in particular, are spending less time on such activities ${ }^{(12)}$, possibly due to increased participation in the labour force. As this demographic shift has coincided with an increase in childhood obesity prevalence, some speculate that there is a relationship between the two ${ }^{(13-16)}$. However, research findings are mixed: studies of nutritional intake find no association between nutritional intake and maternal employment ${ }^{(13,14)}$, while more recent research on the relationship between maternal employment and health outcomes (e.g. obesity) has found a positive association ${ }^{(15,16)}$.

In Germany, there has been a significant increase in maternal labour force participation over the last 30 years, as approximately $65 \%$ of mothers are employed ${ }^{(17)}$. The prevalence of obesity among German adolescents has 
increased by $50 \%{ }^{(18)}$ over the last 30 years. Germany provides an interesting context in which to study associations between maternal employment and children's nutrition-related behaviours, because of persistent postreunification regional differences in institutions and wages $^{(17,19,20)}$. Higher salaries increase the 'value of time', making it more expensive for women to spend time in home-based nutrition-related activities as opposed to market work ${ }^{(21)}$. Thus, there may be regional (East $v$. West Germany) differences in the associations between mother's time use on nutrition-related behaviours and maternal labour force participation.

In the present paper we examine one possible mechanism underlying the association between childhood obesity and maternal employment: that of mothers' and children's time spent in nutrition-related behaviours. To our knowledge, the only nationally representative study that examines children's time use in health activities is a study by Fertig et $a l .{ }^{(22)}$ on a US sample. The authors hypothesized that maternal employment constrains time available for mothers to provide supervision and role modelling of healthy dietary behaviours, such as home meal preparation or eating together as a family. As hypothesized, Fertig et al. found that additional (work) time constraints have a negative influence on the time children spend in nutrition-related behaviours ${ }^{(22)}$.

However, one weakness in the study of Fertig et al. was that children's time use was reported by their mothers. Our study examined the German context using a nationally representative time-use data set in which both mothers and children self-reported time use. We examined the associations between children's and mothers' time spent in nutrition-related behaviours and mothers' labour force participation, accounting for regional differences between East and West Germany. The three outcomes examined were the time spent by children eating meals at home and away from home and the time spent by their mothers in meal preparation. Studying time spent on nutrition-related behaviours among mother-child dyads is important to develop programmes, policies and environments supportive of healthy nutrition behaviours among children.

\section{Methods}

\section{Setting and participants}

Individual-level data on time spent in different activities and selected socio-economic, demographic and household characteristics were derived from the German Time Budget Survey (GTBS), which was carried out by the German National Statistical Office in 2001/02. Nayga ${ }^{(23)}$ points out that available time-use data like the American Time Use Survey have significant limitations, as data are only collected for one person per household. The GTBS, however, is a rich source of time-use data since responses are available for both mothers and their children aged
10-17 years. These data can be used to derive deeper insights into the mechanisms through which maternal employment may be associated with childhood obesity via nutrition-related behaviours. Furthermore, instead of relying on mothers' self-reports of children's time use, the survey measures time use within mother-child dyads and thus allows for a more objective assessment of role modelling of nutrition-related behaviours. The study surveyed approximately 5400 households with more than 12000 individuals over 10 years of age and collected time diaries, recorded in 10-min intervals over a $3 \mathrm{~d}$ period. During the survey, each household member was assigned the same days to record time use, which included two weekdays and one weekend day. Substantive and methodological details of the GTBS are described elsewhere ${ }^{(24)}$. In order to obtain the GTBS data, the first author (A.M.) certified that the privacy of respondents and data would be protected.

For the present analysis we used a subsample of the GTBS data consisting of children between the ages of 10 and 17 years and their mothers living in 1071 twoparent households. We included 4675 person-days of observation for children as some households had more than one child with a time diary.

\section{Dependent variables}

We computed time per day spent by children in each of the following nutrition-related behaviour settings: eating food away from home and eating food at home. We calculated time use in two different situations: children's meals consumed alone $v$. joint meals with mothers. We assume that mother-child dyads eat together if both recorded conducting the same activity (eating) at the same time and the same place (at home or away from home).

We also studied mothers' time spent preparing meals. Time spent on home food preparation may be a proxy for healthier food options, as time-saving convenience products or takeaway foods are often energy dense and nutrient poor ${ }^{(25)}$. Food preparation included time spent cooking/baking, setting the table, washing up and food preservation techniques.

\section{Independent variables}

To measure mothers' labour force participation, we used the mothers' self-reported employment status, a dichotomous variable coded as 1 if the mother reported working full time or part time. We also considered the following factors which may be associated with mothers' and children's time use and were thus considered potential confounders: individual characteristics of the mother and the child, household structure, household resources and day of the week. A dichotomous variable for region was also included in the model to account for regional differences. These could be the result of institutional structures that were developed during the post World War II separation of the two regions ${ }^{(20)}$. For example, women with children 
in West Germany are more likely to be employed part-time than East German women ${ }^{(19)}$. To allow the association between nutrition-related behaviours and maternal labour force participation to differ across regions, we also include an interaction term for region and maternal labour force participation. This interaction would account for a differential response to maternal labour force participation which could come about from persistent differentials in wages post reunification ${ }^{(26)}$.

\section{Statistical analysis}

To handle the frequent occurrence of zero observations in time-use data, we used a double-hurdle model ${ }^{(27)}$. In the first part of the model we applied a probit regression to predict the probability of a person spending time in an activity. In the second part, we used truncated regression models to explore the associations between time spent on nutritional behaviours and maternal labour force participation. In order to make the results comparable in all of the regression models, the same set of independent variables was included in all estimations. We estimated the associations between maternal labour force participation and five nutrition-related behaviours as recorded by the amount of time spent by: the child eating at home alone, the child eating at home with the mother, the child eating food away from home alone, the child eating food away from home with the mother and the mother in meal preparation. Data management and analysis were performed using the STATA SE statistical software package version $10 \cdot 0$ (StataCorp LP, College Station, TX, USA). To account for the fact that there are up to three observations per person in the data (because respondents recorded time diaries for $3 \mathrm{~d}$ ), standard errors were corrected for clustering at the household level ${ }^{(28)}$.

\section{Results}

\section{Descriptive statistics}

Table 1 shows demographic differences between mothers in West and East Germany. Mothers in East Germany worked more, both in terms of the percentage who worked and the number of hours worked. These mothers were also more likely to be of lower socio-economic status (SES), as measured by the poverty level and wage rate. Further, households in East Germany were less likely to own time-saving household appliances (e.g. dishwashers).

Table 2 confirmed the hypothesized associations between maternal employment, region and time spent on nutritionrelated activities. Among households with employed mothers, children spent less time on joint meals at home than their counterparts in households with non-employed mothers ( 9 min less in West Germany; 24 min less in East Germany). In both regions, joint meals by children and their mothers were less likely in households if the mother was working (West: 71\%; East: 67\%) than not (West: $81 \%$, East: $80 \%)$. Further, children of employed mothers spent more time eating alone at home (West: 6 min more; East: 7 min more).

Table 1 Descriptive statistics for explanatory variablest: subsample of children between the ages of 10 and 17 years and their mothers (n 1071), German Time Budget Survey 2001/02

\begin{tabular}{|c|c|c|c|c|c|}
\hline \multirow[b]{2}{*}{ Variable } & \multirow[b]{2}{*}{ Definition } & \multicolumn{2}{|c|}{ West Germany } & \multicolumn{2}{|c|}{ East Germany } \\
\hline & & Mean & SD & Mean & SD \\
\hline \multicolumn{6}{|l|}{ Personal characteristics of the mothers } \\
\hline $\begin{array}{l}\text { Proportion of mothers who work a } \\
\text { positive number of hours }\end{array}$ & Labour force participation of women in sample & 0.45 & 0.50 & $0 \cdot 75$ & $0 \cdot 43$ \\
\hline Mother's hours of work & Own statement of mothers (h:min/week) & $27: 19$ & $13: 12$ & $38: 03$ & $8: 19$ \\
\hline Age & Age (years) & $41 \cdot 45$ & $4 \cdot 74$ & $38 \cdot 79$ & $4 \cdot 31$ \\
\hline Education & $\begin{array}{l}\text { Educational level ( } 1=\text { Diploma to attend university or faculty } \\
\text { of applied science; } 0=\text { lower education) }\end{array}$ & $0 \cdot 30$ & $0 \cdot 46$ & $0 \cdot 22$ & $0 \cdot 41$ \\
\hline Wage & Wage rate $(€ / h)$ of employed mothers & $9 \cdot 76$ & $5 \cdot 89$ & $7 \cdot 70$ & $3 \cdot 66$ \\
\hline \multicolumn{6}{|l|}{ Personal characteristics of the children } \\
\hline Age & Age (years) & $13 \cdot 15$ & $2 \cdot 23$ & $13 \cdot 34$ & $2 \cdot 09$ \\
\hline Gender & Gender child ( $1=$ male; $0=$ otherwise) & 0.51 & 0.50 & 0.50 & 0.50 \\
\hline \multicolumn{6}{|l|}{ Household structure } \\
\hline No. of children under 10 years & $\begin{array}{l}\text { Youngest child in household ( } 1=\text { youngest child under } \\
10 \text { years; } 0=\text { otherwise) }\end{array}$ & $0 \cdot 34$ & $0 \cdot 47$ & $0 \cdot 16$ & $0 \cdot 36$ \\
\hline Only child & $\begin{array}{l}\text { Number of children in household ( } 1=\text { one child; } 0=\text { two } \\
\text { children or more) }\end{array}$ & $0 \cdot 16$ & $0 \cdot 37$ & $0 \cdot 22$ & 0.42 \\
\hline \multicolumn{6}{|l|}{ Household resources } \\
\hline Household income & Household income $(1=<1500 € /$ month; $0=\geq 1500 € /$ month $)$ & 0.03 & $0 \cdot 18$ & 0.09 & 0.28 \\
\hline Freezer & Freezer $(1=$ yes; $0=$ no $)$ & $0 \cdot 82$ & 0.39 & 0.63 & 0.48 \\
\hline Microwave & Microwave $(1=$ yes; $0=$ no $)$ & $0 \cdot 78$ & 0.41 & 0.74 & 0.44 \\
\hline Dishwasher & Dishwasher $(1=$ yes; $0=$ no $)$ & $0 \cdot 88$ & 0.33 & $0 \cdot 70$ & 0.46 \\
\hline \multicolumn{6}{|l|}{ Other } \\
\hline Weekend day & $\begin{array}{l}\text { Weekend day ( } 1=\text { Saturday or Sunday; } 0=\text { Monday to } \\
\text { Friday) }\end{array}$ & $0 \cdot 31$ & $0 \cdot 46$ & 0.32 & 0.47 \\
\hline
\end{tabular}

†The results reported are estimated using sampling weights. 
Table 2 Time use of mothers and children on an average dayt: subsample of children between the ages of 10 and 17 years and their mothers ( $n$ 1071), German Time Budget Survey 2001/02

\begin{tabular}{|c|c|c|c|c|c|c|c|c|c|c|}
\hline \multirow[b]{3}{*}{ Time spent on... } & \multicolumn{4}{|c|}{ Households with employed mothers } & \multirow[b]{3}{*}{$P$ value } & \multicolumn{4}{|c|}{ Households with non-employed mothers } & \multirow[b]{3}{*}{$P$ value } \\
\hline & \multicolumn{2}{|c|}{ East } & \multicolumn{2}{|c|}{ West } & & \multicolumn{2}{|c|}{ East } & \multicolumn{2}{|c|}{ West } & \\
\hline & Mean & $\%$ & Mean & $\%$ & & Mean & $\%$ & Mean & $\%$ & \\
\hline Eating at home alone, child & $0: 35^{\mathrm{a}}$ & $80 \cdot 0$ & $0: 38^{a}$ & $84 \cdot 2$ & 0.068 & $0: 28^{b}$ & $79 \cdot 3$ & $0: 32^{\mathrm{b}}$ & $78 \cdot 5$ & 0.062 \\
\hline Eating at home, mother \& child & $0: 29^{a}$ & $67 \cdot 0$ & $0: 31^{\mathrm{a}}$ & $70 \cdot 6$ & 0.276 & $0: 53^{b}$ & $80 \cdot 3$ & $0: 40^{\mathrm{b}}$ & $80 \cdot 8$ & 0.001 \\
\hline $\begin{array}{l}\text { Eating away from home alone, } \\
\text { child }\end{array}$ & $0: 10$ & $22 \cdot 9$ & $0: 07$ & $16 \cdot 7$ & 0.060 & $0: 13$ & $20 \cdot 7$ & $0: 07$ & $14 \cdot 6$ & 0.044 \\
\hline $\begin{array}{l}\text { Eating away from home, } \\
\text { mother \& child }\end{array}$ & $0: 06^{a}$ & $10 \cdot 4$ & $0: 04$ & $5 \cdot 3$ & $0 \cdot 166$ & $0: 02^{b}$ & $5 \cdot 6$ & 0:05 & $7 \cdot 1$ & 0.005 \\
\hline Preparing meal, mother & $1: 03^{a}$ & $88 \cdot 4$ & $1: 10^{a}$ & $88 \cdot 0$ & 0.069 & $1: 39^{b}$ & $91 \cdot 3$ & $1: 43^{b}$ & $95 \cdot 4$ & 0.419 \\
\hline
\end{tabular}

tMean value of time spent on the various nutrition-related activities ( $\mathrm{h}: \mathrm{min} / \mathrm{d})$ and the percentage of respondents who participated in the activity in a day for all respondents with a time diary. Data are weighted to be representative of the population.

$\ddagger P$ value for the same household type in different regions ( $t$ test).

${ }^{\mathrm{a}, \mathrm{b}}$ Mean values within a row with unlike superscript letters were significantly different between households with employed and non-employed mothers in the same region $(P<0.05)$.

Furthermore, results revealed that the children of nonemployed mothers were less likely to eat away from home compared with children of employed mothers. Children spent $10 \mathrm{~min}$ on eating alone away from home in both regions, independent of mother's employment status.

Employed mothers spent on average around $30 \mathrm{~min}$ less on meal preparation than their non-employed counterparts. Further, mothers living in households in East Germany spent less time on cooking than mothers in West Germany.

\section{Regression model results}

The results of the second stage of the multivariate doublehurdle model are summarized in Table 3 and show that maternal employment was associated with time spent in nutrition-related behaviours of children. Conditional on taking part in any activity, maternal employment was associated with children spending less time eating with their mothers at home and more time eating alone at home. Time spent in other nutrition-related behaviours, such as food preparation, was also associated with maternal labour force participation. Working was associated with a 58 min decrease in time spent by the mother in meal preparation, which is considerably higher than the effect estimated using the means in Table 2 (East: $36 \mathrm{~min}$; West: $33 \mathrm{~min}$ ) because the second stage models the amount of time spent conditional on time spent participating in the specific activity in question. For nutrition-related behaviours outside the home, the results were significant and positively associated with maternal employment for time spent on joint meals away from home. The effect for children eating alone away from home was not statistically significant.

When we examined the associations by region, we found significant differences only for the child eating at home with the mother. For East German children, maternal employment was associated with decreased time spent eating with the mother at home by 14 min compared with 51 min for West German children. The associations between nutrition-related behaviours and the regional indicator support our hypothesis that it is important to account for region. Results demonstrate that East German children were more likely to eat at home alone, less likely to spend time eating at home with their mother, but more likely to eat food away from home with their mother when compared with West German children.

\section{Discussion}

The GTBS data are unique because they have information on how both mothers and children allocate time. Here we exploited this unique feature of the data to study the relationship between maternal employment, mother's time use and child's time use in West and East Germany. We confirmed plausible mechanisms for the association between maternal employment and nutrition-related behaviours. Among children aged 10 to 17 years, maternal employment was associated with an increase in the time children spent eating alone at home as well as a decrease in the time spent eating at home together with their mother. This is a noteworthy finding as joint family meals have been associated with children consuming a healthier $\operatorname{diet}^{(7-9)}$. Our findings corroborate those of others positing that the increase in consumption of food away from home and the increase in obesity are related to increased 'value of time' as more women join the labour force ${ }^{(21)}$.

The regional differences in maternal labour force patterns and cultural orientations ${ }^{(19)}$ provide an interesting case study in which to examine how mothers' employment patterns may be associated with nutrition behaviours among children and their mothers. There were strong regional differences in the amount of time that children spent eating at home alone and away from home in East $v$. West Germany, but differential effects of maternal labour force participation were found for only one activity: eating together at home. The negative associations for this activity were greater in 
absolute value for West Germany than East Germany, confirming the theories put forward by previous studies ${ }^{(21)}$.

While the GTBS is a rich source of time-use data on both mothers and their children, there are some limitations. First, no health data were collected. In the future, the joint collection of time-use and health data among all household members would lead to further insights on how maternal employment might be associated with health. Second, no information on the quality of the food provided to children is given. However, we are able to distinguish between meals eaten at home and away from home, which could serve as a proxy for meal healthfulness. Third, in our study we focus on primary activities. If working mothers engage in multi-tasking then our model might overestimate the association between maternal employment and time spent on nutrition-related behaviours.

We found a negative association between mothers' labour force participation and time spent in children's nutrition-related healthy behaviours, such as eating family meals together. Our results indicate that there are still regional differences between West and East Germany in nutrition-related behaviours and one statistically significant difference in the association between maternal work and these behaviours. The notable differences in the labour force patterns of East $v$. West German women could be driving these statistical findings. Future interventions and policies in both West and East Germany should consider the role of maternal time use in development of supports for facilitating healthy eating behaviours among children, ultimately to prevent obesity.

\section{Acknowledgements}

This research received no specific grant from any funding agency in the public, commercial or not-for-profit sectors. The authors affirm that the submission represents original work that has not been published previously, that is not currently being considered by another journal and that, being accepted for Public Health Nutrition, will not be published elsewhere. All authors have seen and approved the contents of the submitted manuscript. The authors wish to declare no conflicts of interest. A.M. designed the study, provided the data set, analysed and interpreted the data, and wrote the initial draft of the manuscript. S.E.C. and S.B.J. assisted in designing the study, interpretation of the data, and preparing the manuscript. They provided statistical advice. R.M.N. designed the study and assisted in preparation of the manuscript.

\section{References}

1. Ritchie LD, Welk G, Styne D et al. (2005) Family environment and pediatric overweight: what is a parent to do? J Am Diet Assoc 105, Suppl. 1, S70-S79.

2. Savage JS, Fisher JO \& Birch LL (2007) Parental influence on eating behavior: conception to adolescence. J Law Med Ethics 35, 22-34. 
3. Koehly LM \& Loscalzo A (2009) Adolescent obesity and social networks. Prev Chronic Dis 6, 99.

4. Birch LL (1999) Development of food preferences. Annu Rev Nutr 19, 41-62.

5. Birch LL \& Fisher JO (1998) Development of eating behaviors among children and adolescents. Pediatrics 101, 1539-1549.

6. Story M, Neumark-Sztainer D \& French S (2002) Individual and environmental influences on adolescent eating behaviours. J Am Diet Assoc 102, Suppl. 1, S40-S51.

7. Neumark-Sztainer D, Hannan P, Story M et al. (2003) Family meal patterns: associations with sociodemographic characteristics and improved dietary intake among adolescents. J Am Diet Assoc 103, 317-322.

8. Videon T \& Manning CM (2003) Influences on adolescent eating patterns: the importance of family meals. J Adolesc Health 32, 365-373.

9. Matthew W, Gillman MD, Sheryl L et al. (2000) Family dinner and diet quality among older children and adolescents. Arch Fam Med 9, 235-240.

10. Kelder SH, Perry CL, Klepp KI et al. (1994) Longitudinal tracking of adolescent smoking, physical activity, and food choice behaviors. Am J Public Health 84, 1121-1126.

11. Herman KM, Craig CL, Gauvin L et al. (2009) Tracking of obesity and physical activity from childhood to adulthood: the Physical Activity Longitudinal Study. Int J Pediatr Obes 4, 281-288.

12. Hamermesh DS (2007) Time to eat: household production under increasing income inequality. Am J Agric Econ 89, 852-863.

13. Johnson RK, Smiciklas-Wright $\mathrm{H}$, Crouter AC et al. (1992) Maternal employment and the quality of young children's diets: empirical evidence based on the 1987-1988 Nationwide Food Consumption Survey. Pediatrics 90 245-249.

14. Johnson RK, Crouter AC \& Smiciklas-Wright H (1993) Effects of maternal employment on family food consumption patterns and children's diets. J Nutr Educ 25, 130-133.

15. Anderson PM, Butcher KF \& Levine PB (2003) Maternal employment and overweight children. $J$ Health Econ 22 , 477-504.

16. Hawkins SS, Cole TJ \& Law C (2008) Maternal employment and early childhood overweight: findings from the UK Millennium Cohort Study. Int J Obes (Lond) 32, 30-38.

17. Statistisches Bundesamt (2010) Alles beim Alten: Mütter stellen Erwerbstätigkeit hinten an. http://www.destatis.de/ jetspeed/portal/cms/Sites/destatis/Internet/DE/Navigation/ Publikationen/STATmagazin/2010/Arbeitsmarkt2010_03, templateId $=$ renderPrint.psml_nnn $=$ true $\quad$ (accessed July 2010).

18. Kurth B-M \& Schaffrath Rosario A (2007) Die Verbreitung von Übergewicht und Adipositas bei Kindern und Jugendlichen. Ergebnisse des Kinder- und Jugendgesundheitssurveys (KiGGS). Bundesgesundheitsblatt 50, 736-743.

19. Pfau-Effinger B \& Smidt M (2011) Differences in women's employment patterns and family policies: Eastern and Western Germany. Community Work Fam 14, 217-232.

20. Matysiak A \& Steinmetz S (2008) Finding their way? Female employment patterns in West Germany, East Germany, and Poland. Eur Sociol Rev 24, 331-345.

21. Chou S-Y, Grossman M \& Saffer H (2004) An economic analysis of adult obesity: results from the Behavioral Risk Factor Surveillance System. J Health Econ 23, 565-587.

22. Fertig A, Glomm G \& Tchernis R (2009) The connection between maternal employment and childhood obesity: inspecting the mechanisms. Rev Econ Houseb 7, $227-255$

23. Nayga RM Jr (2008) Nutrition, obesity and health: policies and economic research challenges. Eur Rev Agric Econ 35, 281-303.

24. Ehling M, Holz E \& Kahle I (2001) Erhebungsdesign der Zeitbudgetstudie 2001/2002. Wirtschaft und Statistik 6, 427-436.

25. Guthrie JF, Lin BH \& Frazao F (2002) Role of food prepared away from home in the American diet, 1977-78 versus 1994-96: changes and consequences. J Nutr Educ Behav 34, 140-150.

26. Smolnya K \& Kirbacha M (2011) Wage differentials between East and West Germany: are they related to the location or to the people? Appl Econ Lett 18, 873-879.

27. Cragg JG (1971) Some statistical models for limited dependent variables with application to the demand for durable goods. Econometrica 39, 829-844.

28. Wooldridge JM (2002) Econometric Analysis of Cross Section and Panel Data. Cambridge, MA: MIT Press. 